\title{
A nova institucionalidade brasileira e os riscos às práticas afrorreligiosas
}

\section{The new Brazilian institutionality and the risks to Afro-religious practices}

\author{
Valdevino José dos Santos Júnior ${ }^{\mathrm{a}}$ (อ)
}

Resumo As religiões de matriz africana sempre encontraram dificuldades de manifestação no território brasileiro e os seus praticantes passaram a sofrer com múltiplas adversidades, como a intolerância religiosa e a proibição-criminalização de liturgias em Unidades de Conservação (UC). Atualmente, com a nova institucionalidade político-econômico-religiosa de extrema direita brasileira, as adversidades podem estar sendo efervescidas, gerando ameaças aos afrorreligiosos. Nesse sentido, o presente artigo tem como objetivo verificar se as religiões de matriz africana se encontram em risco e/ou limitação de manifestação litúrgica em UC. Verificou-se que a nova institucionalidade brasileira, tal como se caracteriza, é uma geradora de riscos socioambientais e religiosos e tem limitado e colocado, sob risco de perda, os direitos de manifestações afrorreligiosas, a partilha e a liberdade religiosa em UC. A partir disso, o pensar em serviços ecossistêmicos culturais em UC, como aqueles que trazem benefícios religiosos e espirituais às pessoas, pode contribuir para a construção de políticas públicas democráticas, partilhando o meio ambiente sem restrições, respeitando a visão de uma população geralmente excluída, valorizando tradições, garantindo liberdade religiosa e desenvolvimento sustentável e humano com liberdade. Palavras-chave Religiões afro-brasileiras. Intolerância religiosa. Extrema direita. Conservadorismo. Política.

Abstract The African Matrix religions have always encountered difficulties in manifesting themselves in Brazilian territory and their practitioners have suffered from multiple adversities, such as religious intolerance and prohibitioncriminalization of liturgies in protected areas (PA). Nowadays, with the new political-economic-religious institutionality of the far right in Brazil, adversities may be effervescing, generating threats to Afro-religious practitioners. In this sense,

a Doutorando no Programa de Pós-Graduação em Meio Ambiente da Universidade do Estado do Rio de Janeiro (PPGMA/UERJ). Pesquisador do grupo de pesquisa MEANDROS - Estudos Interdisciplinares sobre Ciências, Tecnologias e Políticas Públicas em Saúde e Ambiente no Laboratório de Informação Científica e Tecnológica em Saúde, Fundação Oswaldo Cruz (LICTS/ FIOCRUZ).E-mail: valdonjsantos@hotmail.com. 
this article aims to verify if religions of African origin are at risk and / or limited by liturgical manifestation in PA. It was found that the new Brazilian institutionality, as it is characterized, is a generator of socio-environmental and religious risks, and has limited and placed at risk of loss the rights of Afro-religious manifestations, sharing and religious freedom in PA. From this, thinking about cultural ecosystem services in $P A$, such as those that bring religious and spiritual benefits to people, can contribute to the construction of democratic public policies, sharing the environment without restrictions, respecting the vision of a population generally excluded, valuing traditions, guaranteeing religious freedom and sustainable and human development with freedom.

Keywords Afro-Brazilian religions. Religious intolerance. Far right. Conservatism. Politics.

\section{INTRODUÇÃO}

As religiões de matriz africana sempre encontraram dificuldades de manifestação desde o seu florescimento no território brasileiro, devido ao desconhecimento dos fundamentos filosóficos de suas liturgias. Os praticantes dessas religiões passaram a sofrer com intolerância religiosa (CAMPos; Rubert, 2014; Nogueira, 2020), proibição-criminalização de liturgias (SOBREIRA, 2011), como também racismo ambiental (Lima; OliveIra, 2016; MACHADO; VILANI; SobreIRA, 2017), racismo institucional e injustiça ambiental atreladas ao preconceito racial (Costa, 2008).

Historicamente, houve e há casos em que praticantes de religiões de matriz africana tiveram o direito de liberdade religiosa impedido ao adentrarem em uma Unidade de Conservação (UC) federal e, ainda, as suas práticas religiosas são tidas como criminosas. De fato, são recorrentes os ataques a uma minoria religiosa (SobreIRA, 2011), representada por apenas 0,3\% da população brasileira, conforme o censo 2010 do Instituto Brasileiro de Geografia e Estatística (IBGE, 2012).

No ano de 2019, foram relatadas 354 denúncias por discriminação religiosa no Disque 100 (Disque Direitos Humanos). Dentre as religiões das vítimas mais atacadas estão a umbanda (26), o candomblé (18), o espiritismo (18), as de matrizes africanas (18), a católica (12) e as testemunhas de Jeová (12). Em 2018, foram relatadas 506 denúncias de discriminação religiosa, sendo as mais atacadas a umbanda (72), o candomblé (47), as testemunhas de Jeová (31), as de matrizes africanas (28) e alguns segmentos evangélicos (23). No ano anterior, em 2017, foram relatadas 537 denúncias, prevalecendo novamente a discriminação religiosa sobre os praticantes de religiões de matrizes africanas (BRASIL, 2020). 
Por conseguinte, convivemos com um exacerbamento da intolerância religiosa em todo o planeta (ACN, 2018) e no Brasil o maior número de casos envolve conflitos entre neopentecostais e afrorreligiosos. Assim, as causas da religião ter ocupado os pódios mais altos de conflitos ao longo dos últimos anos e a razão pela qual aquelas de matriz africana são as mais perseguidas dão-se analogamente ao estabelecimento do regime econômico neoliberal global (CAVALCANTI, 2016) da extrema direita e das igrejas evangélicas neopentecostais (LOPEs, 2019).

Vivemos em um mundo diverso (Machado, 2019), contudo o que se tem verificado no Brasil é a ascensão da direita e da extrema direita, do conservadorismo, das frentes neopentecostais e do capitalismo neoliberal (GENTILE, 2018; SANTOS, 2018), reforçando conceitos de individualidade, segregação, privatização, desdemocratização, quebra da laicidade do Estado, desregulamentações sociais e ambientais, apelo aos militares e concessões de privilégios às elites (FERREIRA, 2016; Gentile, 2018; Ghiraldelli JÚNior, 2019; IASI, 2015; LöWy, 2015; Machado, 2012; Machado, 2019; Machado; Vilani; Sobreira, 2017; Maitino, 2018; Nogueira, 2020). Quando essa visão de mundo se torna dominante, as demais visões são ofuscadas e reprimidas, direitos e liberdades são restringidos, impedindo o desenvolvimento humano digno, o livre exercício de liturgias e o acesso às Unidades de Conservação, como previsto na Constituição Federal de 1988 (CF/88).

Nesse contexto, cabe se perguntar se, diante da nova institucionalidade político-econômico-religiosa de extrema direita brasileira - de destruição da política ambiental brasileira e restrição de direitos socioambientais legalmente instituídos -, as práticas religiosas de matriz africana estariam correndo o risco de perda e/ ou limitação de direitos de manifestações em espaços públicos de conservação ambiental (UC).

A partir dessa perspectiva, o presente artigo objetiva responder a essa questão de forma afirmativa - apresentando um conjunto de argumentos - a partir da premissa metodológica de Machado (2012) e Machado, Vilani e Sobreira (2017), que consiste em pensar a realidade a partir do substrato, do lócus onde se dão os acontecimentos no território em que se vive com retrocesso normativo, destruição socioambiental, ascensão dos interesses religiosos neopentecostais e das forças de mercado tutelando a democracia. Para tanto, o texto está dividido em três seções, além da introdução e da conclusão. Na primeira seção, é realizada uma breve revisão de literatura sobre as religiões de matriz africana no Brasil, a fim de compreender seu surgimento no território brasileiro, suas tradições, práticas litúrgicas e o contato com a natureza, bem como as discriminações, os racismos e a intolerância pelos quais os praticantes são acometidos. Em seguida, a nova institu- 
cionalidade brasileira é descrita e analisada, procurando-se caracterizar os fatores que geram riscos para as religiões de matriz africana. Na terceira seção, é proposta uma valorização dos serviços ecossistêmicos culturais em UC com a incorporação das práticas religiosas de matriz africana como uma forma de respeitar legalmente a manifestação de tais práticas no meio ambiente natural. Consecutivamente, o artigo é concluído com a avaliação de que a nova institucionalidade brasileira tem ameaçado com a perda e a limitação dos direitos de manifestações das religiões de matriz africana em espaços públicos de conservação ambiental. Além disso, entende-se que a adoção de uma perspectiva sistêmica sobre os serviços ecossistêmicos culturais, como aqueles que trazem benefícios espirituais e religiosos às pessoas, pode contribuir para a resolução de um problema estrutural.

\section{UM BREVIÁRIO DAS RELIGIÕES DE MATRIZ AFRICANA NO BRASIL}

As religiões de matriz africana (e afro-brasileiras) ${ }^{1}$ sempre encontraram dificuldades de manifestação desde seu surgimento no Brasil, em função do desconhecimento dos fundamentos filosóficos de suas liturgias. Consequentemente, os praticantes dessas religiões passaram a sofrer e ainda sofrem com intolerância religiosa, vilipêndio religioso, proibição-criminalização de liturgias e racismos de diversas ordens: ambiental, estrutural e institucional, além de injustiça ambiental, correlacionados ao preconceito racial (CAMURÇA, 2017; CoSTA, 2008; CAMPOS E RUPERT, 2014; Lima e Oliveira, 2016; Machado, Vilani e Sobreira, 2017; Nogueira, 2020; SOBREIRA, 2011).

Acerca disso, pesquisas relatam que no Brasil, entre os séculos XVI e XIX, foram recebidos aproximadamente cinco milhões de africanas e africanos na situação de mulheres e homens escravizados, provenientes de diversas áreas do continente africano, onde atualmente se encontram os países: Angola, Congo, Moçambique, Benin, Guiné, Nigéria e Senegal (BrasiL, 2018).

Segundo Roger Bastide (1961), os negros africanos foram considerados instrumentos indispensáveis para a economia de uma grande propriedade agrícola, sendo somente isso que interessou o homem branco.

Os escravizados trouxeram para o território brasileiro não apenas a sua força de trabalho, mas também o conhecimento que tinham no continente afri-

1 Entende-se aqui como as religiões de matriz africana e afro-brasileira, tal como definido por Goldman (2009, p.106), como um "conjunto algo heteróclito, mas certamente articulado, de práticas e concepções religiosas cujas bases foram trazidas pelos escravos africanos e que, ao longo da sua história, incorporaram em maior ou menor grau elementos das cosmologias e práticas indígenas, assim como do catolicismo popular e do espiritismo de origem européia. Evidentemente, esses elementos transformam-se à medida que são combinados, e vice-versa". 
cano, como o uso de tecnologias agrícolas e de mineração, além das respectivas culturas, saberes, tradições e valores civilizatórios que foram preservados e que estão presentes no povo brasileiro. Além disso, a religiosidade se fez presente na vinda dos africanos para o Brasil, onde três grandes matrizes culturais (Bantu, Ewé Fon e Yorùbá) conseguiram conservar suas cosmovisões e seus saberes, que, por sua vez, estão inseridos na história do Brasil e no modo de vida da sociedade (BRASIL, 2018).

Nessa direção, estudiosos apontam que, junto com as diversas etnias dos escravizados trazidos para o Brasil no período colonial, vieram dispositivos culturais, incluindo religiosos, os quais, mesmo tendo alguns aspectos em comum, tinham variações entre si. Tanto estava presente essa variedade cultural que os donos de escravos procuraram reunir os escravizados de diferentes etnias como forma de criar rivalidades entre os grupos étnicos, dificultando a coesão entre eles e desfavorecendo a formação de famílias. Nesse sentido, ao serem recolocados nos terreiros brasileiros, esses sistemas religiosos estavam imersos de uma diversidade, devido à matriz étnica e territorial africana, que se elevou com o processo de reformulação e disseminação pelo país, adquirindo a "feição regional" do grupo africano matricial. Dessa forma, têm-se no Brasil diversas religiões de origem africana, entre elas, o candomblé (Bahia), o xangô (Pernambuco, Alagoas e Paraíba), o tambor (Maranhão), o batuque e babaçuê (Região Amazônica), o batuque (Rio Grande do Sul), a macumba (São Paulo), a umbanda e a quimbanda (Rio de Janeiro) (Theodoro, 2008).

Os candomblés pertencem a "nações" diversas e perpetuam, portanto, tradições diferentes: Angola, Congo, Gêge (isto é, Ewe), Nagô (têrmo com que os franceses designavam todos os negros de fala yorubá, da Costa dos Escravos), Quêto (ou Ketu), Ijêxa (ou Ijesha). É possível distinguir estas “nações” umas das outras pela maneira de tocar o tambor (seja com a mão, seja com varetas), pela música, pelo idioma dos cânticos, pelas vestes litúrgicas, algumas vezes pelos nomes das divindades e, enfim, por certos traços do ritual (BASTIDE, 1961, p. 17).

A umbanda - fundada no Estado do Rio de Janeiro - é, como consequência, a religião de matriz africana de maior expressão no Estado, tendo se irradiado com êxito pela região Sudeste, principalmente em Minas Gerais e São Paulo, e para a região Sul do Brasil (Theodoro, 2008). Efetivamente, a umbanda está difundida na porção mais populosa do território brasileiro (região Sudeste-Sul) e, segundo 
Sobreira, Machado e Vilani (2016, p. 7), "é o grupo religioso afro-brasileiro de maior representatividade entre a população brasileira, secundado pelo candomblé, originário da Bahia, mais antigo e menos sincretizado do que a umbanda".

No mesmo sentido, Prandi (2003, p. 17) afirmou que "a umbanda conservou do candomblé o sincretismo católico: mais que isto, assimilou preces, devoções e valores católicos que não fazem parte do universo do candomblé. Na sua constituição interna, a umbanda é muito mais sincrética que o candomblé”.

Ademais, os povos tradicionais de matriz africana e de terreiros se reconhecem como unidades de resistência africana, sendo uma importante referência de africanidade presente na sociedade brasileira. Dentre os múltiplos atributos que existem nessa comunidade, pode-se destacar a continuidade do processo civilizatório africano no Brasil, que resulta na constituição de territórios próprios, nos quais há a convivência em comunidade e o acolhimento independente do grau de parentesco sanguíneo, ou a ausência deste parentesco. Nesse contexto, a classe social a qual pertencem não é levada em conta, porque, no momento em que estão inseridos nessa comunidade mediante ritual de iniciação, passam a fazer parte de uma família de axé, onde a hierarquia e o respeito aos mais velhos são fatores fundamentais para a preservação da tradição e dos costumes ali conservados e repassados por meio da oralidade (BRASIL, 2018).

No mesmo viés, José Flávio Pessoa de Barros destaca que:

"Os "terreiros”, "roças”, “casas-de-santo" ou “casas-de-Candomblé” são denominações correntes utilizadas para nomear tanto os espaços como os grupos de culto aos deuses africanos. Estes locais, onde são reverenciados também os ancestrais ilustres, recebem designações (Ketu, Angola, Jêje, etc.) de acordo com as tradições culturais predominantes advindas de suas relações com grupos étnicos africanos. São às raízes da África mítica, reelaboradas no contexto brasileiro, a que tais nomes aludem, reforçando os limites ideológicos entre as comunidades, como também das identidades que tais associações produzem. $\mathrm{O}$ terreiro é, portanto, uma associação liturgicamente organizada, em cujo espaço dá-se a transmissão e a aquisição dos conhecimentos de uma determinada tradição religiosa. Trata-se de um conceito que inclui, além da vivência social em uma determinada cultura, um espaço distinto do contexto onde está inserido. Neste local são forjadas identidades religiosas diferenciadas, com características próprias" (PESSOA DE BARROS, 2011, p. 29). 
Nessa perspectiva, as práticas religiosas de matriz africana são modos de fazer tradicionais e característicos dos sistemas religiosos, envolvendo diversas ações, tais como: atividades de dança, canto, música, artesanato e culinária. Envolvem também atividades que têm caráter fundamentalmente ritualístico e mágico, como o sacrifício de animais, uma prática distintiva do candomblé e o uso terapêutico de ervas, uma prática usada na umbanda (Sobreira; MACHAdO; Vilani, 2016, p. 7).

Acerca do uso de ervas, essa prática é bastante comum nas religiões afro, tanto para fins terapêuticos ritualísticos (BARBOSA JÚNIOR, 2011) quanto medicinais (ARRUDA et al., 2019). O uso de plantas nas religiões de matriz africana globalmente é categorizado em três grandes aspectos, os quais não se excluem, segundo Serra et al. (2002) e é destacado por Silva e Silva (2018). Os aspectos são: (1) o uso ritual ou simpático, para atrair alguma necessidade ou desejo; (2) uso alimentar, na forma de oferendas, sobretudo frutas ou outras partes de plantas que representem o orixá ou a divindade que se queira cultuar; e (3) uso terapêutico, para cura ou revitalização, priorizando as folhas em detrimento das ervas.

No caso da umbanda em particular, Carlessi (2016) definiu em quatro tipos diferentes os grupos de uso: (1) banhos de ervas, (2) chás e defumações, (3) preparo de fundamentos e (4) trabalhos e oferendas.

Dentre outras práticas religiosas comumente realizadas pelas religiões de matriz africana, há o uso de espaços territoriais especialmente protegidos, isto é, UC, concebidas como espaços sagrados para a realização de práticas afrorreligiosas (Sobreira, 2011). Nessa acepção, os espaços sagrados nas UC consistem em áreas que possuem pontos de força de orixás (deidades) e outras entidades cultuadas pelas religiões em questão, como: cachoeiras, rios, lagos, matas, montanhas, afloramentos rochosos, determinadas espécies de árvores, etc.; para a realização de oferendas, banhos e rituais, os quais são fundamentais para as liturgias e a propagação de ensinamentos afrorreligiosos (SANTOS JÚnioR; MACHADO; VIlANi, 2020).

Tais práticas litúrgicas estão, assim, em uma análise preliminar, desfrutando da prerrogativa constitucional de liberdade religiosa elitúrgica (MACHADO; VILANI; Sobreira, 2017; Sobreira; Machado; Vilani, 2016), conforme o art. $5^{\mathrm{o}}$, inciso VI, $\mathrm{CF} / 88$, no qual está escrito que é "inviolável a liberdade de consciência e de crença, sendo assegurado o livre exercício dos cultos religiosos e garantida, na forma da lei, a proteção aos locais de culto e as suas liturgias" (BRASIL, 1988).

No mesmo sentido, o artigo 18 da Declaração Universal dos Direitos Humanos (DUDH) apresenta que: 
Toda pessoa tem direito à liberdade de pensamento, consciência e religião; este direito inclui a liberdade de mudar de religião ou crença e a liberdade de manifestar essa religião ou crença, pelo ensino, pela prática, pelo culto e pela observância, isolada ou coletivamente, em público ou em particular (ORGANIZAÇÃO DAS NAÇÕES UNIDAS - ONU, 1948).

Nessa lógica, segundo Santos (2018), com esse marco conceitual, percebe-se que a liberdade religiosa e litúrgica não é apenas um direito constitucional, é também uma demanda indispensável que precisa ser discutida em âmbito internacional, uma vez que, em uma sociedade de direito, dever-se-ia tutelar pela pluralidade de religiões. Desse modo, isso não é um consenso ideológico e conta, por seu turno, com inúmeras adversidades.

Por conseguinte, colocada em oposição à despersonalização democrática, a cultura de origem afro tende a ser, recorrentemente, criminalizada, seja pelo viés religioso ou pelos aspectos relacionados à cultura. Nesse contexto, Santos (2018) destacou o caso do samba de roda do recôncavo baiano e da roda de capoeira, símbolos do movimento histórico-cultural brasileiro, os quais, somente no final de 2014, foram reconhecidos como patrimônio cultural imaterial da nação pelo IPHAN $^{2}$ e, mais tarde, reconhecidos como patrimônio cultural da humanidade pela UNESCO 3 (UNESCO, 2014).

Sobremaneira, as religiões de matriz africana são uma construção histórico-cultural, que nos remete à sociedade escravocrata brasileira e aos conhecimentos sobre o manejo de uma diversidade biológica ainda desconhecida, do tradicional uso terapêutico de ervas que insistimos em ignorar até hoje. Ainda assim, entre a soberba e a ignorância, crescem os ataques aos praticantes de religiões de matriz africana, ameaçando e colocando em risco suas vidas, costumes, práticas e conhecimentos sobre a biodiversidade brasileira (Machado; Vilani; Sobreira, 2017).

Nesse cenário, vale relembrar o processo de eugenia 4 brasileiro no início do século XX, que tendia à construção de outra realidade nacional, a qual era vista

2 Instituto do Patrimônio Histórico e Artístico Nacional - IPHAN.

3 Organização das Nações Unidas para a Educação, a Ciência e a Cultura - UNESCO.

4 O movimento eugênico brasileiro é um caso particularmente interessante de estudo de ciência e ideologia social. De um lado, a eugenia foi profundamente estruturada pela composição racial e pelas preocupações raciais do país. Em um sentido bem fundamental, a eugenia referia-se à raça e ao aprimoramento racial, não à classe. Isso porque concentrava suas atenções nas doenças que eram vistas como particularmente prevalentes entre os pobres, vale dizer, entre a população principalmente negra ou mestiça. Essa população era percebida como ignorante, doente e cheia de vícios, com altas taxas de alcoolismo, imoralidade, mortalidade e morbidade. Se na cena pública a literatura eugênica utilizava a palavra 'raça' invariavelmente, no singular, 
pelo atraso civilizacional. Isso pressupunha adicionar os valores "brancos", valores relacionados à tentativa de implementar uma cultura europeizada, corroborando para o descrédito de todas as práticas religiosas que não possuíam correspondência com esse modelo. É perceptível, assim, em um país tão heterogêneo com um processo histórico tão peculiar como o Brasil, com enaltecimento de valores europeus e, paradoxalmente, um país mestiço em seu nascimento, a relevância da temática intolerância religiosa encontrar-se ainda tão latente (NoGUEIRA, 2020; SAntos, 2018).

Para Fernandes (2017), é histórica a luta das religiões de matriz africana contra a intolerância religiosa no Brasil. Nesse viés, desrespeito, demonização das deidades afro cultuadas, agressões verbais e físicas, e ataques aos espaços físicos dos terreiros são somente algumas das formas de discriminação e intolerância que os praticantes afrorreligiosos sofrem. De fato, o preconceito e as ações voltados contra tais praticantes têm relação com o processo de formação estrutural do Estado sob a colonial modernidade, dado que, para o colonizador, evangelizar as populações indígenas e africanos escravizados era algo necessário para missão colonial.

No mesmo sentido, Nogueira (2020) chama atenção para o fato de que, desde a invasão dos portugueses, a religião cristã foi empregada para a conquista, dominação e doutrinação, sendo a base de um projeto político dos colonizadores, havendo a aniquilação de qualquer crença que não fosse a imposta pela Coroa Portuguesa em consórcio com o Papado. Formou-se, então, a tríade lei-rei-fé, a qual especificamente referia-se à lei de Portugal, ao rei de Portugal e à fé-religião católica apostólica romana. A partir disso, o que vemos é o apagamento e o silenciamento das crenças de origem africana, ou seja, crenças não eurocêntricas. Notadamente, essas ações se estendem até os dias atuais.

Isso implica que, em pleno século XXI, casos de intolerância religiosa e de racismos, atrelados ao preconceito racial, nos remetem a um passado tenebroso que ainda nos assombram, além de ferir a CF/88, a Declaração de Direitos Humanos e a liberdade religiosa.

No que diz respeito à noção de intolerância religiosa, essa prática consiste na necessidade de estigmatizar para fazer oposição entre o que é normal, regular e padrão, e o que é anormal, irregular e não padrão. Nessa lógica, estigmatizar é um exercício de poder sobre o outro. Estigmatiza-se para excluir, seccionar, ofuscar,

para referir-se ao 'povo brasileiro', na esfera privada ela significava a 'raça negra' (STEPAN, 2004, p. 355-356). 
calar e apartar do grupo tido como normal e prestigiado. Na atualidade, o que é chamado de intolerância religiosa está centrado no processo de colonização do país, como falado anteriormente. Tal processo tem deixado marcas profundas em uma ideia também ilusória de democracia religiosa e laicidade (NogueIRA, 2020), além da promoção de diferentes formas e manifestações de racismo, preconceito e discriminação.

Nessa perspectiva, Almeida (2018, p. 25-26) faz uma diferenciação entre racismo, preconceito e discriminação. Para ele, o racismo "é uma forma sistemática de discriminação que tem a raça como fundamento e que se manifesta por meio de práticas conscientes ou inconscientes que culminam em desvantagens ou privilégios para indivíduos, a depender do grupo racial ao qual pertençam”. O preconceito racial "é o juízo baseado em estereótipos acerca de indivíduos que pertençam a um determinado grupo racializado, e que pode ou não resultar em práticas discriminatórias”. Já a discriminação racial “é a atribuição de tratamento diferenciado aos membros de grupos racialmente identificados"; esta ainda pode ser subdividida em direta e indireta. A discriminação direta "é o repúdio ostensivo a indivíduos ou grupos, motivados pela condição racial”. A discriminação indireta "é um processo em que a situação específica de grupos minoritários é ignorada", ou seja, é dada "pela ausência de intencionalidade explícita de discriminar pessoas". Isso pode dar-se porque uma lei ou prática não considera ou não prevê de forma concreta as consequências da lei. Ainda sobre a discriminação, é possível falar de discriminação positiva, a qual pode ser entendida "como a possibilidade de atribuição de tratamento diferenciado a grupos historicamente discriminados com o objetivo de corrigir desvantagens provocadas pela discriminação negativa - a que gera prejuízos e desvantagens".

Nesse cenário, o racismo, o qual se materializa através de discriminação racial, é definido pelo seu viés sistêmico. Não se trata, portanto, somente de uma ação discriminatória ou mesmo de um conjunto de ações, mas, sim, de "um processo em que condições de subalternalidade e de privilégios que se distribuem entre grupos raciais se reproduzem nas esferas políticas, econômicas e das relações cotidianas" (AlmEIDA, 2018, p. 27).

O preconceito, a discriminação, a intolerância e, no caso das tradições culturais e religiosas africanas, o racismo se caracteriza pelas formas perversas de julgamento que estigmatizam um grupo e exaltam outro, valorizam e conferem prestígios e hegemonia a uma pessoa ou grupos, prejudicando outras pessoas e grupos, sustentados pela ignorância, pelo moralismo, pelo conservadorismo e, atualmente, pelo poder político - os quais culminam em ações prejudiciais e até 
certo ponto criminosas contra um grupo de pessoas com uma crença considerada não hegemônica (NoGUEIRA, 2020).

Essa temática fomentou congressos internacionais, nacionais e regionais, bem como cartas de repúdio escritas pela Associação Brasileira de Histórias da Religião (ABHR) e outras sete associações contra todas as formas de preconceitos, discriminações e intolerâncias. Isso no contexto de instigar a democratização de estudos científicos que têm as religiões e religiosidades como objetos e a atenção a uma conjuntura contemporânea de avanço de um conservadorismo reacionário que coloca em risco e cria obstáculos às conquistas democráticas e cidadãs. Em 2018, a ABHR, dias antes da eleição presidencial, firmou sua posição contrária ao então candidato, hoje presidente, Jair Messias Bolsonaro, considerando-o e até prevendo-o como "danoso à saúde democrática do Brasil" (MARANHão FiLHO, 2018, p. 10). Uma vez que ele, dentre outras coisas abomináveis - como pode ser verificado no trabalho de Nascimento et al. (2018) - fez apologia à tortura em pleno Congresso Nacional, sem que saísse de lá preso (MACHADO, 2019).

Todas estas questões - racismos, intolerância religiosa, discriminação, preconceitos, conservadorismo e fundamentalismo religioso - podem estar sendo efervescidas com a nova institucionalidade brasileira, colocando em risco minorias religiosas e os direitos resguardados pela $\mathrm{CF} / 88$ aos cidadãos e cidadãs brasileiros.

\section{A NOVA INSTITUCIONALIDADE BRASILEIRA E A GERAÇÃO DE RISCOS}

Em 2016, a democracia brasileira tentou lutar contra uma crise política, econômica e institucional, que colocou em risco e vem ameaçando os direitos constitucionais e sociais conquistados nos últimos anos. Dentre as ameaças de um parlamento cada vez mais conservador, está a quebra da laicidade do Estado brasileiro (Sobreira; MACHADO; VILANI, 2016), com o aumento do fundamentalismo religioso, dado pelo crescente avanço da bancada evangélica, cada vez mais presente e forte no campo político brasileiro.

Nesse contexto, Trevisan (2013, p. 582) analisou a Frente Parlamentar Evangélica como sendo uma força política que "não pode mais ser desconsiderada das análises políticas do país”. Observa-se, como consequência, a crescente ameaça de criminalização das práticas religiosas de matriz africana por meio do uso do aparato estatal, por fundamentalistas religiosos, em particular do Poder Legislativo (Sobreira; Machado; Vilani, 2016).

Dessa forma, o recente avanço do conservadorismo, perpetrado por um golpe de Estado parlamentar, midiático e jurídico (MACHADO; VILANI, 2016), alimentou a oposição das elites nacionais que apoiaram o golpe de Estado ao acolher qual- 
quer tipo de política progressista (Machado; Vilani; Sobreira, 2017); com base na adoção, em maior ou menor grau, da racionalidade neoliberal, que valoriza a diversidade típica do individualismo e rejeita a igualdade como um objetivo da política (Metcalf, 2017). Assim, tem sido acentuada no Brasil a presença do conservadorismo e do fundamentalismo religioso, sobretudo evangélico, ditando as regras sobre os direitos constitucionais nos últimos anos (GHIRALDELLI JÚNIOR, 2019; Machado; Vilani; Sobreira, 2017).

Nesse caminho, o proselitismo religioso e eleitoral misturou-se de modo que não se sabe mais o que é religião e o que é política. Com isso, foi jogado fora, da mesma forma, a suposta laicidade do Estado garantido pela CF/88. Nesse mesmo sentido, as forças políticas aliaram-se à demonização das religiões de matrizes africanas, estabelecendo e fortalecendo um projeto de poder e dominação, e a intolerância religiosa tornou-se igualmente um lugar de pseudo-heróis salvadores do Brasil contra vilões responsáveis por todos os males da sociedade e da alma humana (NogueIRA, 2020).

Segundo Silva (2012), os discursos de intolerância religiosa que rebaixam as religiões de matrizes africanas vêm sendo constatados por antropólogos, historiadores e sociólogos em diversos contextos dos séculos XIX e XX. Observa-se também que isso vem se perpetuando ao longo dos anos, como afirma Vagner Gonçalves da Silva (2007), no livro intitulado Intolerância religiosa: o impacto do neopentecostalismo no campo religioso afro-brasileiro. A obra aborda que, nas últimas décadas, houve um aumento dos ataques das igrejas evangélicas neopentecostais contra as religiões de matrizes africanas e que essa situação tem acarretado conflitos de grande repercussão e visibilidade pública.

Algumas dessas situações envolvendo intolerância e vilipêndio religioso contra as religiões de matrizes africanas foram abordadas por Marcelo Camurça (2017), na obra A questão da laicidade no Brasil: mosaico de configurações e arena de controvérsias. Camurça, fugindo do enquadramento teleológico e normativo, buscou construir um mosaico de configurações diferenciadas para expressar as situações de laicidade desiguais, mas que são conviventes entre si no Brasil.

$\mathrm{Na}$ direção da contenção do religioso no espaço público, Camurça (2017) levantou algumas intervenções de agentes públicos alegando valores laicos para coibir a presença de afrorreligiosos. $\mathrm{O}$ autor referiu-se às proposições surgidas na Assembleia Legislativa do Rio Grande do Sul e na Câmara Municipal de Porto Alegre, listadas na pesquisa de Ari Pedro Oro. Reivindicando-se na matéria de "higiene urbana", proibiram-se a colocação de animais mortos em locais públicos, tornando esta prática sujeita a multas; assim como outra que proibia sacrifício de 
animais em nome do Código de Defesa dos Animais. Oro afirmou que a proposta foi feita por um deputado evangélico e associa estas medidas a "exemplos recentes de tentativa de discriminação das religiões afro-brasileiras" (ОRо, 2011, p. 229) e "na tentativa de tolhimento à liberdade religiosa de reprodução ritualística desse meio religioso" (ORO, 2011, p. 229, NOTA 7).

O interessante é que mesmo tendo como protagonista um deputado evangélico, não é - neste caso - o discurso religioso que envolve o projeto, mas, sim, questões "sanitárias" e "éticas", muitas vezes também desenvolvidas por agentes civis laicos e "progressistas" contra o "obscurantismo" religioso (CAMURÇA, 2017, p. 876).

Na sequência, aprofundaremos a questão controversa da laicidade no Brasil, mas agora focando no período das eleições para Presidência da República em 2018, quando houve, de fato, a efetivação da nova institucionalidade abordada no presente artigo.

Sobre isso, Ronaldo de Almeida (2019, p. 35) ilustrou que, antes do presidente eleito Jair Bolsonaro fazer o discurso da vitória, passou a palavra ao senador, pastor e cantor gospel Magno Malta (PR-SE), que disse: "Nós começamos essa jornada orando. E o mover de Deus... e ninguém vai explicar isso nunca: os tentáculos da esquerda jamais seriam arrancados sem a mão de Deus. Começamos orando e mais do que justo que agora oremos para agradecer a Deus". Depois disso, pediu que todos dessem as mãos e iniciou uma oração típica de igrejas evangélicas pentecostais. Declarou, entre outras coisas, que a diversidade das religiões no Brasil desejava Bolsonaro, sem deixar de mencionar, porém, que o Brasil é majoritariamente cristão. Ao fim, rogou em nome de Jesus e, em coro com todos os presentes, declarou o bordão da campanha: "Brasil acima de tudo e Deus acima de todos".

Segundo Almeida (2019), as sinalizações de Bolsonaro foram fortes rumo ao bloco evangélico, que, além de significativo demograficamente, pode ser, em boa medida, alinhado eleitoralmente. Bolsonaro declara-se católico; contudo, o pastor Silas Malafaia, da Assembleia de Deus, foi quem realizou seu casamento com uma evangélica. O filho, deputado federal Eduardo Bolsonaro, é batista. Depois da votação do impeachment de Dilma Rousself na Câmara dos Deputados, em 2016, Bolsonaro foi batizado pelo pastor Everaldo, da Assembleia de Deus, no rio Jordão, em Israel, apesar de ter sido batizado quando criança no catolicismo. O batismo católico não tem validade para os evangélicos, pois não se trata de uma decisão autônoma e consciente. Os evangélicos (pastores e políticos) foram primordiais para a campanha presidencial em 2018. As citações bíblicas tomaram conta dos discursos durante as eleições. Sobre a facada que levou, ele narrou a história como um testemunho evangélico. Antes do seu primeiro pronunciamento como 
presidente eleito, houve uma típica oração evangélica e não com um Pai Nosso, tão menos de uma Ave Maria. Na verdade, como ato falho, a imagem de Nossa Senhora Aparecida foi exposta na casa de Bolsonaro depois de eleito; antes no primeiro turno, uma menorá (candelabro judaico) fazia parte do cenário quando ele deu uma entrevista à TV Record. Falou ainda no decorrer da campanha que, se eleito, reconheceria Jerusalém como a capital de Israel.

Dessa forma, até a composição do novo governo, Bolsonaro fez acenos à grande chave "cristã", o que não incluiu referências específicas às religiões espíritas e de matrizes africanas (estas últimas, sendo, mais uma vez, invisibilizadas), porém adicionou o judaísmo como compreendido pelo evangelismo de matriz fundamentalista norte-americana. O presidente vem se apresentando como um cristão, sem levantar a bandeira católica e sempre sinalizando para os evangélicos que pode ser, aparentar ou tornar-se evangélico (AlmeidA, 2019).

Para Boaventura de Sousa Santos ${ }^{5}$, o que também ocorre no Brasil é uma tóxica combinação entre neoliberalismo e conservadorismo religioso. Assim, o evangelismo neopentecostal converte desigualdade em resignação, pois o rico é aquele que foi abençoado por Deus. De fato, o colonizador foi-se, mas ficou o legado colonial, ainda muito marcante, como se mostra o patriarcado e o racismo. E com a nova institucionalidade, tendo Bolsonaro como capitão, o capitalismo brasileiro endurece: aumentando o extermínio racial, a ocupação das favelas, o machismo, etc. (SILVA, 2019); bem como atitudes racistas que recaem sobre as minorias como povos indígenas e afrodescendentes (SANTOS, 2018).

Nessa conjuntura, a racionalidade neoliberal atrelada ao conservadorismo em expansão no mundo (DARDOT; LAVAL, 2016), e especialmente no Brasil (MACHADO; VILANI; SOBREIRA, 2017), e associada à ascensão das religiões evangélicas (sobretudo, neopentecostais) dentro de um projeto conservador, atualmente em conflito com a democracia (NogueIra, 2020), tem colocado em risco as práticas religiosas de matriz africana nos espaços sagrados dentro de Unidades de Conservação.

Sobre isso, foi determinado ao poder público, no art. $225, \S 1^{\circ}$, inciso III, da $\mathrm{CF} / 88$, o dever de definir, em todas as unidades da federação, espaços territoriais e seus componentes a serem especialmente protegidos com objetivos de assegurar a efetividade do direito ao meio ambiente ecologicamente equilibrado (BrasiL, 1988; Pereira; Scardua, 2008).

5 Entrevista à Carta Maior. Disponível em: https://www.cartamaior.com.br/?/Editoria/Politica/ Boaventura-de-Sousa-Santos-Por-que-o-Neoliberalismo-de-fachada-democratica-so-resiste-no-Brasil-/4/45712. Acesso em: 29/10/2020. 
Contrariamente, Costa (2008) dissertou que o modelo de conservação ambiental aplicado no Brasil tem fundamentos ideológicos coloniais/modernos, capitalista, eurocêntrico e racista, de perfil autoritário e territorializante. Nesse modelo foram instituídas categorias de UC para uso indireto, acarretando a expulsão de grupos tradicionais de seus territórios de gênese, pertencimento e identidade, sobretudo na categoria Parque Nacional, segregando o homem e sua cultura, estabelecendo arenas de disputas e conflitos no contexto de acesso e uso dos recursos naturais. Isso causa impactos negativos em etnias vulnerabilizadas que, desterritorializadas, sofrem com a proibição ou a falta de condições materiais e simbólicas para reprodução de suas práticas culturais, para estabelecer e reproduzir seus modos tradicionais de uso da natureza a que culturalmente pertencem, ficando ameaçadas de perda e de fragmentação de identidades.

A título de exemplo, o Parque Nacional da Tijuca (PNT), localizado na cidade do Rio de Janeiro, é um espaço territorial federal especialmente protegido, onde secularmente negras e negros realizavam suas práticas religiosas cultuando deidades, as quais são realizadas até os dias de hoje, bem como outras 10 religiões e espiritualidades. Contudo, apenas as religiões de matriz africana sofrem ataques, racismos ambiental, estrutural e institucional, e intolerância religiosa (CosTA, 2008), além dessas práticas religiosas, por vezes, serem tidas como criminosas (Sobreira, 2011).

O Parque Nacional da Tijuca é uma modalidade de UC $^{6}$ que não permite nenhuma prática que cause danos aos recursos naturais daquele ecossistema ou à paisagem, sendo apenas permitidas atividades para fins educacionais, científicos, recreativos e turísticos. Norteados por essa perspectiva, os funcionários do PNT impediram que os afrorreligiosos depositassem oferendas em áreas de florestas e cachoeiras do Parque, por entenderem que tais práticas religiosas ocasionavam "impactos" ao meio ambiente (Boniolo, 2018). Apesar de o PNT contar com capelas e um dos maiores símbolos católicos e monumento histórico em seu território, o Cristo Redentor - o qual fomenta a economia turística no Rio de Janeiro -, a religião católica não sofre ataques no referido Parque.

Quanto a essa matéria, Sobreira (2011) pesquisou sobre práticas religiosas de matriz africana no PNT e ilustrou o caso de proibição-criminalização por meio de uma placa na entrada do Parque, a qual colocava a realização de oferendas no mesmo contexto de crime que: caçar, jogar lixo fora dos coletores e retirar plantas,

6 São áreas consideradas relevantes por sua paisagem ou pelos recursos ambientais encontrados na localidade, dependendo da modalidade admite o uso, ou não, dos recursos. A modalidade parque nacional não admite esse uso (BonIOLO, 2018). 
tendo, todas elas, o mesmo valor infracional, ou seja, a prática de fazer oferendas às deidades, algo que é comum nas religiões de matriz africana, "é despida de seu caráter sagrado e travestida de crime ambiental”. O autor segue argumentando que,

No aspecto legal, os diplomas, que segundo a interpretação da administração [do PNT] embasam a proibição são o Decreto 84.017/79 e a Lei 9.605/98. O primeiro contém o Regulamento dos Parques Nacionais Brasileiros (como são criados e qual sua finalidade); o segundo diploma é a Lei de Crimes Ambientais, que dá suporte, segundo os gestores do PNT, a que as oferendas sejam consideradas crimes. Ora, se um interdito é baseado em uma lei criminal (que prevê os crimes e as respectivas penas), é porque está se querendo dizer, com esta fundamentação, que tais condutas proibidas são crimes (SobreIRA, 2011, p. 18).

Essa proibição-criminalização incorre em contradição, se pensarmos que ela ocorre em um país onde a Constituição Federal garante a liberdade religiosa e de local de culto. Com base na interpretação das normas ambientais e do direito constitucional à liberdade de crença e de consciência, o livre exercício de cultos religiosos é garantido e assegurado, conforme disposto no artigo $5^{\circ}$, VI, da CF/88 (Sobreira, 2011; Sobreira; Machado; Vilani, 2016).

Legalmente, são os praticantes de religiões de matriz africana os detentores da garantia de realização de liturgias junto ao meio ambiente natural, uma vez que matas, rios, pedreiras e cachoeiras são locais sagrados de culto. As liturgias não violam os princípios da Política Nacional do Meio Ambiente, não se configurando, dessa forma, uma ameaça à proteção de ecossistemas ou uma atividade potencialmente degradadora do meio ambiente (SOBREIRA, 2011).

No entanto, com a nova institucionalidade brasileira, tendo um Executivo Federal (Governo Bolsonaro) marcado por atuar e bater recordes de assinaturas "as canetadas" - em atos e decretos7 (CASTRO, 2019; ENFPT, 2019), as áreas sagradas em UC e o meio ambiente como um todo, estão em risco.

Ainda no contexto de riscos da nova institucionalidade ao meio ambiente, conforme levantamento da Folha de S.Paulo em parceria com o Instituto Talanoa ${ }^{8}$,

7 Fonte: AgÊNCIA Estado. Disponível em: https://www.correiobraziliense.com.br/app/noticia/politica/2019/o6/o4/interna_politica,760088/bolsonaro-edita-recorde-de-decretos-desde-collor. shtml. Acesso em: 27/09/ 2020.

8 Fonte: Redação Jornal de Brasília. Disponível em: https://jornaldebrasilia.com.br/politica-e-poder/governo-acelerou-canetadas-sobre-meio-ambiente-durante-a-pandemia/. Acesso em: 29/09/ 2020. 
o Executivo Federal acelerou a publicação de atos no Diário Oficial sobre o meio ambiente. Entre os atos, têm-se portarias, instruções normativas, decretos e outras normas, relacionados à temática ambiental. Foram publicados no período de março a maio de 2020, 195 atos e, no mesmo período de 2019, foram publicados somente 16 atos, ou seja, 12 vezes mais atos que no ano anterior. Os atos do Executivo, de forma ampla, servem para direcionar o cumprimento das leis e complementar sua aplicação. Porém, a análise também aponta que uma parte dessas medidas infralegais tentou mudar o entendimento da legislação.

$\mathrm{O}$ resultado do levantamento foi ao encontro do que o Ministro do Meio Ambiente, Ricardo Salles, defendeu na reunião ministerial de 22 de abril de 2020, cujo teor veio a público em maio, após decisão do Supremo Tribunal Federal. Sobre isso, o Ministro disse: "precisa ter um esforço nosso aqui enquanto estamos neste momento de tranquilidade no aspecto de cobertura de imprensa, porque só se fala de Covid, e ir passando a boiada e mudando todo o regramento e simplificando normas" (sic).

Especialistas e entidades relacionadas ao meio ambiente interpretaram na declaração referida a confissão de que o ministro Salles buscava, com o uso de atos infralegais, o desmonte de políticas ambientais previstas em lei, em que as modificações, portanto, deveriam passar pelo Legislativo. Sobremodo, no exame dos principais atos publicados, verifica-se o caminho de desregulamentações no setor ambiental. Entre elas, tem-se a reforma administrativa do ICMBio, órgão responsável pela gestão das UC no Brasil. De fato,

Na prática isso significou uma redução de 11 para 5 no número de servidores responsáveis por 335 Unidades de Conservação em todo Brasil. Além disso, a portaria abriu a possibilidade para que as posições pudessem ser ocupadas por pessoas fora do órgão. O resultado foi que das cinco gerências do ICMBio, apenas uma é ocupada por um agente de carreira do órgão. As outras quatro são comandadas por policiais militares. A alteração é outro exemplo de mudança infralegal, porque não precisou passar pela chancela do Legislativo, e entrou em vigor imediatamente (NICOLAV, 2020).

Ainda na reunião interministerial, o ministro Salles arguiu em defesa de agir num esforço para alterar a legislação vigente: 
"De IPHAN [Instituto do Patrimônio Histórico e Artístico Nacional], de Ministério de Meio Ambiente, de ministério disso, de ministério daquilo. Agora é a hora de unir esforços pra dar de baciada a simplificação de regulamentos”. Salles também criticou a atuação da Justiça, que segundo ele age para barrar as tentativas de alterações normativas propostas por ele. "Tudo que a gente faz é pau no Judiciário, no dia seguinte”. Segundo ele, a estratégia seria passar novas desregulamentações ambientais "e deixar a AGU [Advocacia-Geral da União] de stand by [prontidão] pra cada pau que tiver". Além de se indispor com o Judiciário, o ministro também minimizou o papel do Congresso com relação à proteção do meio ambiente. "Não precisamos de Congresso. Porque coisa que precisa de Congresso também, nesse fuzuê que está aí, nós não vamos conseguir aprovar. Agora tem um monte de coisa que é só, parecer, caneta, parecer, caneta" (Alessi, 2020).

Com isso, no dia 25 de setembro de 2020, foi anunciado que um coronel da Polícia Militar assumiria o comando das UCs do Brasil, tornando mais que escancarada a militarização do ICMBio e as consequentes nomeações sem legitimidades técnicas. Na verdade, o profissional não tem experiência anterior na área ambiental (ISA, 2020). Nesse sentido, na escolha de profissionais duvidosos, o ministro Ricardo Salles pode ter escolhido alguém questionável tanto quanto ele, pelo menos, até onde se sabe, o coronel (ainda) não inventou ter obtido um falso grau de mestre pela Universidade de Yale (Estados Unidos) ${ }^{9}$.

Nesse cenário, Ghiraldelli Júnior (2019), na crítica ao presidente Bolsonaro e aos conservadores, diante caráter predatório e de descuido para com as florestas, relembrou que o atual Ministro do Meio Ambiente, Ricardo Salles, é:

[...] nada mais, nada menos que um condenado pela Justiça Federal de São Paulo por fraudar processo de plano de manejo da área de proteção ambiental da várzea do rio Tietê. Mais um feito do Bolsonaro que, se não me falhe a memória, pode ser considerado inédito: o Ministro do Meio Ambiente da República é criminoso contra o meio ambiente! (GHIRALDELLI JÚNIOR, 2019, P. 102).

Com essas constatações sobre a nova institucionalidade brasileira, a qual promove um "desenvolvimento" que compromete, dentre outras coisas, o meio

9 Fonte: Demori, Leandro. Disponível em: <https://theintercept.com/2019/02/23/ricardo-salles-yale-mentira/>. Acesso: 30/09/ 2020 
ambiente e o futuro, sem partilha e sem liberdade. Na atual conjuntura no Brasil, pode-se perceber os diversos riscos, os quais a sociedade brasileira está sendo exposta, implicando impactos negativos e profundos sobre o direito ao meio ambiente ecologicamente equilibrado, ferindo, mais uma vez, uma garantia constitucional. Porém, agora é o art. 225 da CF/88 que está sendo atingido.

Nessa direção, os praticantes de religiões de matrizes africanas são um alvo fácil da nova institucionalidade brasileira, a qual tem gerado diversos riscos aos espaços sagrados afrorreligiosos existentes em UC. Esses espaços são imprescindíveis aos praticantes de religiões de matriz africana, para que eles tenham liberdade religiosa, liberdade para fazer oferendas, além de usar e compartilhar serviços ecossistêmicos culturais religiosos providos pelas UC.

Nesse sentido, pensar em serviços ecossistêmicos culturais em unidades de conservação torna-se necessário para fazer valer as garantias previstas na $\mathrm{CF} / 88$ e na Declaração Universal dos Direitos Humanos.

\section{OS SERVIÇOS ECOSSISTÊMICOS CULTURAIS EM UNIDADES DE CONSERVAÇÃO: POR UM FUTURO DE PARTILHA E LIBERDADE}

Os ecossistemas são extremamente fundamentais para garantir as condições e processos necessários à vida humana. Inclui-se também a manutenção da base física para atividades econômicas e todas as demais complexas estruturas sociais e culturais. Apesar dessa relevância, a conservação, a manutenção e a recomposição dos ecossistemas está cada dia mais ameaçada (YounG; SPANHoli, 2020), sobretudo, com a nova institucionalidade brasileira, como anteriormente demonstrado, tem afetado negativamente a provisão dos serviços ecossistêmicos (SE).

Conforme o Millennium Ecosystem Assessment (MEA, 2005), os SE podem ser definidos como: "os benefícios que as pessoas obtêm dos ecossistemas". Todos os ecossistemas naturais produzem serviços, tais como: produção de alimentos e medicamentos, fornecimento de solos produtivos e água potável, proteção contra desastres naturais, oportunidades de recreação, manutenção do patrimônio cultural, benefícios religiosos/espirituais, entre outros.

Acerca dos serviços ecossistêmicos culturais (SEC), os quais podem ser definidos como: "benefícios não materiais que as pessoas obtêm dos ecossistemas através do enriquecimento religioso e espiritual, desenvolvimento cognitivo, reflexão, recreação e experiências estéticas” (MEA, 2005). Na concepção do The Economics of Ecosystem an Biodiversity (TEEB, 2010), os SEC são as contribuições diretas e indiretas dos ecossistemas para a cultura e as relações sociais de um determinado grupo social. 
O conceito de SEC parte do entendimento das culturas nas quais está inserido, e, por consequência, como as culturas são fortemente influenciadas pelos ecossistemas que as circundam, estando relacionado aos aspectos como modos de vidas tradicionais e a presença de religiões e cosmologias específicas (GVCES, 2017).

Nesse sentido, Milcu et al. (2013) apontou que os SEC são essenciais para a identidade cultural e até mesmo para a sobrevivência de comunidades tradicionais. Pode-se incluir também os terreiros de matrizes africanas (NogueIra, 2020).

Então, o Brasil, com seu território de dimensão continental e variedade de ambientes, é um dos países com maior riqueza biológica no mundo. E, de tal forma, associada à exuberância natural, o país contém uma expressiva pluralidade social, representada por 235 etnias indígenas e centenas de grupos tradicionais não-indígenas, que revelam uma riqueza tanto cultural quanto biológica (ISA, 2011; LeWINSOHN; Prado, 2005).

Além disso, as fontes de águas sagradas também são muito significativas no território nacional (Fernandes-Pinto; Irving, 2015). Quanto essa questão, em uma ampla revisão sobre a temática, Lazzerini e Bonotto (2014) mapearam 102 localidades no território brasileiro onde há fontes de águas vinculadas a rituais, crenças, poderes míticos ou propriedades curativas para povos indígenas, populações tradicionais, religiões de matriz africana, catolicismo e sincretismos. Essas fontes são fortes indutoras de desenvolvimento sustentável e sua proteção deve ser fomentada, devido, entre outros aspectos, às dimensões simbólicas, como: fonte de vida, meio de purificação, regeneração, fertilidade, sabedoria, graça, virtude e revelação do sagrado.

Em razão disso, Fernandes-Pinto (2017) listou 115 UC, nas quais foram registradas a ocorrência de áreas sagradas para o uso religioso de elementos naturais, sendo que 58 são UC federais, 42 UC estaduais e 15 UC municipais. Nesse caso, há uma predominância de 80 UC de proteção integral, federais, estaduais e municipais - na categoria Parques, foram identificadas 76 UC. Isso ilustra a dimensão e a importância dos SEC religiosos/espirituais providos pelas UC ao povo brasileiro. São esses locais que estão em risco com a nova institucionalidade brasileira, a qual fomenta degradação socioambiental, conforme argumentado anteriormente.

Ora, as Unidades de Conservação são espaços territoriais especialmente protegidos, onde há áreas naturais tidas como sagradas para a realização de liturgias e rituais para as deidades cultuadas pelas religiões de matriz africana, como já apontado, e, nesse sentido, as UC devem ser pensadas para esses fins litúrgicos (Machado; Vilani; Sobreira, 2017). 
Segundo Irving (2010), apesar de a literatura sobre áreas sagradas em UC no Brasil atentar-se, principalmente, aos conflitos socioambientais que permeiam essas situações, algumas vantagens potenciais para a proteção da natureza também são reconhecidas por alguns autores, que enfatizam a importância de que nas estratégias de conservação da natureza sejam integrados e valorizados os atributos históricos e culturais, isto é, os SEC. Como também a importância e necessidade de adicionar os SEC ao processos decisórios (DANIEL et al., 2012).

É possível notar, as práticas que estão enraizadas em costumes, crenças, conhecimentos, visões de mundo e valores das populações locais (e comunidades tradicionais de matriz africana) contribuem para a conservação do meio ambiente e, consequentemente, dos SEC. Assim, para Lazzereini e Bonotto (2014), o conhecimento tradicional sobre o ecossistema desempenha funções essenciais na proteção de recursos hídricos e de florestas, as quais protegem mananciais de bacias hidrográficas.

A tendência internacional aponta para a maior proteção das áreas naturais tradicionais ou sagradas em UC, em função do aspecto conjuntural de valores tangíveis e intangíveis que as áreas simbolizam, como: antropológicos, artísticos, bem-estar, científicos, culturais, educacionais, espirituais, estéticos, existenciais, históricos, paz, recreativos, serviços ecossistêmicos, tradicionais, terapêuticos e turísticos (Fernandes-Pinto; Irving, 2017; Gray; Hancock, 2007; Wild; Mcleod, 2008).

São nos locais de áreas sagradas onde o poder público e os afrorreligiosos podem atuar no contexto de proteção e preservação de UC. Desse modo, fica evidente as vantagens sociais, ambientais e econômicas compatíveis com desenvolvimento sustentável (WILD; MCLEOD, 2008).

Diante do atual contexto brasileiro de avanço do conservadorismo e do crescimento da bancada evangélica pentecostal na representação política, e seus riscos sobre minorias, grupos e populações vulneráveis às situações sociais em âmbito nacional agravam da mesma forma as condições ambientais da Natureza deteriorada (MAchado; VILANI; SOBREIRA, 2017).

Assim, a discussão dos SEC em UC pode, entre outros, servir de base teórica para o compartilhamento da experiência social, religiosa, cultural e ambiental que sensibiliza e humaniza a sociedade, deixando-a mais solidária e fraterna (MACHADO; Vilani; Sobreira, 2017). Sendo possível, portanto, assegurar os direitos constitucionais e humanos, garantindo a liberdade religiosa, a partilha e o uso de áreas consideradas sagradas para a realização de práticas religiosas de matriz africana sem restrições e limitações. 


\section{À GUISA DE CONCLUSÃO}

O presente artigo teve como objetivo mostrar que as religiões de matriz africana encontram-se em risco com a nova institucionalidade brasileira que, na atual conjuntura político-econômico-religiosa de extrema direita, tem limitado e colocado sob risco de perda os direitos de manifestações afrorreligiosas em espaços públicos de conservação ambiental.

Tendo em vista os argumentos expostos, a nova institucionalidade brasileira não apenas tem colocado em risco as religiões de matriz africana, como também: i) promove ações racistas, injustas, preconceituosas e discriminatórias; ii) evidencia o conservadorismo; iii) estimula o fundamentalismo religioso; iv) quebra a laicidade do Estado; v) ressalta o neoliberalismo; vi) fomenta a degradação social e ambiental; vii) fere os direitos humanos e constitucionais; viii) coloca em risco o desenvolvimento humano e sustentável; ix) instiga a criminalização de religiões de matriz africana e; x) ameaça os espaços sagrados em Unidades de Conservação.

Em suma, a nova institucionalidade - tal como ela se qualifica -, fomenta e intensifica os riscos e limita as manifestações afrorreligiosas em UC. Impossibilita, portanto, um futuro com partilha e liberdade. Para contribuir com a prerrogativa de Machado, Vilani e Sobreira (2017), no sentido de eliminar o risco de criminalização das práticas religiosas de matriz africana, pensar em SEC em UC pode ser uma forma de adicionar ao debate subsídios para a construção de um Estado democrático e laico, e para a formação de uma sociedade solidária e pluricultural. Da mesma forma, contribuir para a proteção do ambiente ecologicamente equilibrado e dos saberes tradicionais associados, valorizando-os e incorporando-os aos processos decisórios.

Diante dessa realidade, a adoção de uma perspectiva sistêmica sobre os serviços ecossistêmicos culturais, trazendo benefícios espirituais e religiosos às cidadãs e aos cidadãos brasileiros, pode contribuir para a resolução de um problema estrutural. Esse olhar de inclusão pode nos ajudar a construir políticas públicas democráticas, partilhando o meio ambiente sem restrições, respeitando a visão de uma população geralmente excluída, valorizando tradições e garantindo a liberdade religiosa.

\section{REFERÊNCIAS BIBLIOGRÁFICAS}

ACN - Aid to the Church in Need. Liberdade Religiosa no Mundo: sumário executivo. São Paulo: ACN, 2018.

Alessi, Gil. Salles vê "oportunidade" com coronavírus para "passar de boiada” desregulação da proteção ao meio ambiente. El País Brasil, 2020. Disponivel em: https://brasil. 
elpais.com/brasil/2020-05-22/salles-ve-oportunidade-com-coronavirus-parapassar-de-boiada-desregulacao-da-protecao-ao-meio-ambiente.html. Acesso em: 24/09/2020.

AlmeidA, Ronaldo da. Deus acima de todos. In: Democracia em risco?: 22 ensaios sobre o Brasil hoje. São Paulo: Companhia das Letras, 2019.

Almeida, Sílvio Luiz de. O que é racismo estrutural? Belo Horizonte: Letramento, 2018. ArrudA, Deliane Andrade de. et al. Uso de plantas medicinais na Umbanda e Candomblé em associação cultural no município de Puxinanã, Paraíba. Revista Verde de Agroecologia e Desenvolvimento Sustentável, Pombal, v. 14, n. 5, 2019.

BARBoSA JúNIOR, Ademir. Curso essencial de Umbanda. São Paulo: Universo dos Livros, 2011. BASTide, Roger. O candomblé da Bahia: rito nagô. Tradução de Le candomblé de Bahia: (rite Nagô), de 1958. São Paulo: Nacional, 1961.

Boniolo, Roberta Machado. “Como ordenar o que não pode ser ordenado?”: criação de regras de uso do Espaço Sagrado da Curva do S (Parque Nacional da Tijuca/Rio de Janeiro). Cadernos de campo, Sao Paulo, v. 27, n.1, 2018.

Brasil. Balanço - Disque 100. Ministério da Mulher, da Família e dos Direitos Humanos, 2020. Disponivel em: https://www.gov.br/mdh/pt-br/acesso-a-informacao/ouvidoria/ balanco-disque-100. Acesso em: 16/09/2020.

Brasil. Comunidades Tradicionais de Matriz Africana. Ministério da Mulher, da Família e dos Direitos Humanos, 2018. Disponivel em: https://www.gov.br/mdh/pt-br/ navegue-por-temas/igualdade-racial/comunidades-tradicionais/comunidadestradicionais-de-matriz-africana. Acesso em: 16/09/2020.

Brasil. Constituição da República Federativa do Brasil. Brasília: Senado Federal; Centro Gráfico, 1988.

CAMURÇA, Marcelo Ayres. A questão da laicidade no Brasil: mosaico de configurações e arena de controvérsias. Horizonte, Belo Horizonte, v. 15, n. 47, p. 855-886, jul./set., 2017.

CAmpus, Isabel Soares; Rubert, Rosane Aparecida. Religiões de matriz africana e intolerância religiosa. Cadernos do LEPAARQ, Pelotas, v. 11, n. 22, 2014.

CARLESSI, Pedro Crepaldi. "Nessas matas tem folhas!" Uma análise sobre 'plantas'e 'ervas' a partir da umbanda paulista. 2016. 104 f. Dissertação (Mestrado em Ciências). Universidade Federal de São Paulo. Diadema, 2016.

CASTRo, Grasielle. Bolsonaro tem recorde de decretos de costumes entre os últimos presidentes, 2019. Disponível em: https://www.huffpostbrasil.com/entry/bolsonarodecretos-costumes_br_5cfae6e3e4bo4e9ofic9802b. Acesso em: 23/10/2020.

Cavalcanti, Ana Paula Rodrigues. Relações entre preconceito religioso, preconceito racial e autoritarismo de direita: uma análise psicossocial. Tese (Doutorado em 
Psicologia Social). João Pessoa: Programa de Pós-Graduação em Psicologia Social da Universidade Federal da Paraíba, 2016.

Costa, Lara Moutinho da. A floresta sagrada da Tijuca: estudo de caso de conflito envolvendo uso público religioso de Parque Nacional. Dissertação (Mestrado em Psicossociologia de Comunidades e Ecologia Social). Rio de Janeiro: Universidade Federal do Rio de Janeiro, 2008.

DANiel, Terry. et al. Contributions of cultural services to the ecosystem services agenda. PNAS, v. 109, n. 23, p. 8812-8819, Jun 2012.

Dardot, Pierre; Laval, Christian. A nova razão do mundo: ensaio sobre a sociedade neoliberal. São Paulo: Boitempo, 2016.

ENFPT - Escola Nacional de Formação do PT. Retrocessos do governo Bolsonaro. ENFPT, 2019. Disponivel em: https://www.enfpt.org.br/retrocessos-do-governo-bolsonaro/\#. Acesso em: 23/10/2020.

FERnandes-Pinto, Érika. Sítios naturais sagrados no Brasil: inspirações para o reencantamento das áreas protegidas. Rio de Janeiro: Univesidade Federal do Rio de Janeiro, 2017.

FERnANDEs-Pinto, Érika; Irving, Marta de Azevedo. "Sítios Naturais Sagrados no Brasil: o gigante desconhecido". In: HanAzAKI, N. E. A. Culturas e Biodiversidade: o presente que temos e o futuro que queremos. Florianópolis: [s.n.], 2015. p. 397-408.

FERnANDEs-PInTo, Érika; IRving, Marta de Azevedo. Sítios naturais sagrados: valores ancestrais e novos desafios para as políticas de proteção da natureza. Desenvolvimento Meio Ambiente. Curitiba: v. 40, p. 275-296, abr., 2017.

Ferreira, Guilherme Gomes. Conservadorismo, fortalecimento da extrema-direita e a agenda da diversidade sexual e de gênero no Brasil contemporâneo. Lutas Sociais. São Paulo: v. 20, n. 36, p. 166-178, jan./jun. 2016.

Gentile, Fábio. A direita brasileira em perspectiva histórica. Plural. São Paulo: v. 25, n. 1, p. 92-110, 2018.

GHIRALdelli JÚNior, Paulo. A filosofia explica Bolsonaro. São Paulo: LeYa, 2019.

Gray, Martin; Hancock, Graham. Sacred Earth: places of peace and power. New York: Sterling Publishing Co, 2007.

Gvces - Centro de Estudos em Sustentabilidade da Fundação Getulio Vargas. Caso empresarial de valoração não econômica de Serviços Ecossistêmicos Culturais. A relação da Assessa e da Comunidade da Praia da Baleia com as algas marinhas. São Paulo: GVces, 2017.

IASI, Mauro Luis. De onde vem o conservadorismo? Blog da Boitempo, 2015. Disponivel em: https://blogdaboitempo.com.br/2015/04/15/de-onde-vem-o-conservadorismo/. Acesso em: 23/10/2020. 
IBGE - Instituto Braslieiro de Geografia e Estatística. Censo 2010: número de católicos cai e aumenta o de evangélicos, espíritas e sem religião. Censo 201O, 2012. Disponivel em: https://censo2010.ibge.gov.br/noticias-censo?id=3\&idnoticia=2170\&view=not icia. Acesso em: 22/09/2020.

Irving, Marta de Azevedo. Áreas Protegidas e Inclusão Social: uma equação possível em políticas públicas. Sinais Sociais, Rio de Janeiro, v. 4, p. 122-147, 2010.

Isa - Instituto Socioambiental. Coronel da PM vai assumir comando das Unidades de Conservação no país. Instituto Socioambiental, 2020. Disponivel em: https://www. socioambiental.org/pt-br/blog/blog-do-monitoramento/coronel-da-pm-vai-assumircomando-das-unidades-de-conservacao-no-pais. Acesso em: 28/o9/2020.

Isa - Instituto Socioambiental. Povos Indígenas no Brasil: 2005/2010. SÃO PAULO: [S.N.], 2011.

Lazzerini, Fábio Tadeu; Bonotto, Daniel Marcos. Fontes de águas “milagrosas” no Brasil. Ciência e Natura, Santa Maria, v. 36, n. especial II, p. 559-572, 2014.

FERNANDEs, Nathalia Vince Esgalha. A raiz do pensamento colonial na intolerância religiosa contra religiões de matriz africana. Calundu, Brasília, v. 1, n. 1, p. 117-136, jan./jun. 2017.

Lewinsohn, Thomas. M.; Prado, Paulo Inácio. Quantas espécies há no Brasil? Megadiversidade, v. 1, n. 1, p. 36-42, 2005.

Lima, Kellen Josephine Muniz de; OliverRA, Ilzver de Matos. Racismo ambiental e aupressão de espaços litúrgicos naturais das religiões de matriz africana: dilemas entre políticas públicas de preservação ambiental e de proteção às manifestações culturais afrobrasileiras.Prim@ Facie, v. 15, n. 28, p. 01-34, abr 2016.

LOPES, Rodrigo. Boaventura de Sousa Santos: "A esquerda deixou de falar com as periferias". GZH, 2019. Disponivel em: https://gauchazh.clicrbs.com.br/politica/noticia/2019/o7/ boaventura-de-sousa-santos-a-esquerda-deixou-de-falar-com-as-periferiascjxyyok4soosoo1msxph7hqfa.html. Acesso em: 10/10/2020.

Löwy, Michael. Conservadorismo e extrema-direita na Europa e no Brasil. Serviço Social \&. Sociedade., São Paulo, n. 124, p. 652-664, out./dez. 2015.

Machado, Carlos José Saldanha. Ciências, Políticas Públicas e Sociedade Sustentável. Rio de Janeiro: E-papers, 2012.

Machado, Carlos José Saldanha. Ensaio sobre o mundo da rudeza dos fatos: breviário do Brail e engajamento das ciências ambientais. 1. ed. Rio de Janeiro: E-papers, 2019. Machado, Carlos José Saldanha; Vilani, Rodrigo Machado. Temas e problemas da vida em sociedade no Brasil. Rio de Janeiro: E-papers, 2016. 
Machado, Carlos José Saldanha; Vilani, Rodrigo Machado; Sobreira, Ramon Fiori Fernandes. Práticas religiosas afro-brasileiras e as ciências ambientais. Rio de Janeiro: E-papers, 2017.

Maitino, Martin Egon. "Direita, sem vergonha”: conformações no campo da direita no Brasil a partir do discurso de Jair Bolsonaro. Plural. São Paulo, v. 25, n. 1, p. 111-134, 2018.

Maranhão Filho, Eduardo Meinberg de Albuquerque. Política, Religião e Diversidades: Educação e Espaço Público. Florianópolis: ABHR/Fogo, v. I, 2018.

Mea - Millennium Ecosystem Assessment. Ecosystems and Human Well-being: Synthesis. Washington: [S.N.], 2005.

Metcalf, Stephen. Neoliberalism: the idea that swallowed the world. The Guardian, 2017. Disponivel em: https://www.theguardian.com/news/2017/aug/18/neoliberalism-theidea-that-changed-the-world. Acesso em: 11/09/2020.

Milcu, Andra Ioana et al. Cultural Ecosystem Services: A Literature Review and Prospects for Future Research. Ecology and Society, v. 18, n. 3, 2013.

Nascimento, Leonardo. et al. "Não falo o que o povo quer, sou o que o povo quer": 30 anos (1987-2017) de pautas políticas de Jair Bolsonaro nos jornais brasileiros. Plural, São Paulo, v. 25, n. 1, p. 135-171, 2018.

Nicolav, Vanessa. O que passou na "boiada" de Ricardo Salles durante a pandemia? Brasil de Fato, 2020. Disponivel em: https://www.brasildefato.com.br/2020/o6/o9/o-quepassou-na-boiada-de-ricardo-salles-durante-a-pandemia. Acesso em: 24/o9/2020. Nogueira, Sidnei. Intolerância religiosa. São Paulo: Sueli Carneiro: Pólen, 2020.

Organização Das Nações Unidas. Declaração Universal dos Direitos Humanos. Paris: ONU, 1948.

Oro, Ari Pedro. A laicidade no Brasil e no Ocidente. Algumas considerações. Civitas, Porto Alegre, v. 11, n. 2, p. 221-237, 2011.

PrANDI, Reginaldo. As religiões afro-brasileira e seus seguidores. Civitas, Porto Alegre, v. 3, n. 1, jun 2003.

Pereira, Polyana. Faria; Scardua, Fernando Paiva. Espaços territoriais especialmente protegidos: conceito e implicações jurídicasEspaços territoriais especialmente protegidos: conceito e implicações jurídicas. Ambient. Soc, Campinas , v. 11, n. 1, p. 81-97, jun 2008.

Pessoa de Barros, José Flávio. O espaço sagrado nos candomblés nagô. Revista del Cesla, Varsóvia, n. 14, 2011.

SILVA, Maria Rejane da. Intolerância e demonização das práticas religiosas afro-brasileiras na cidade de Petrolina/PE nos anos 40 e 70. In: X Encontro Estadual ANPUH História e contemporaneidade. Petrolina: 2012. 
SANTos, Boaventura de Sousa. Esquerdas do mundo, uni-vos! São Paulo: Boitempo, 2018. SANTos, Wéllia Pimentel. História, cultura, intolerância acerca das religiões de matrizes africanas no Brasil. Calundu, Brasília, v. 2, n. 1, p. 5-22, jan./jun. 2018.

Santos Júnior, Valdevino José dos; Machado, Carlos José Saldanha; Vilani, Rodrigo Machado. Não existe futuro sem partilha: pensando os serviços ecossistêmicos culturais em unidades de conservação e práticas religiosas de matriz africana no Brasil. In: XXXII Reunião Brasileira de Antropologia. Rio de Janeiro: 2020.

Serra, Ordep et al. O mundo das folhas. Salvador: Universidade Estadual de Feira de Santana, 2002.

SiLva, João Batista da. Boaventura de Sousa Santos: 'Por que o Neoliberalismo de fachada democrática só resiste no Brasil?”. Carta Maior, 2019. Disponivel em: https://www. cartamaior.com.br/?/Editoria/Politica/Boaventura-de-Sousa-Santos-Por-que-oNeoliberalismo-de-fachada-democratica-so-resiste-no-Brasil-/4/45712. Acesso em: 24/09/ 2020.

Silva, Matheus Colli; Silva, Vagner Gonçalves da. Um bosque de folhas sagradas: o Santuário Nacional da Umbanda e o culto da natureza. Interagir: pensando a extensão, Rio de Jnaiero, n. 26, p. 11-33, jul/dez, 2018.

SiLvA, Vagner Gonçalves da. Intolerância religiosa: o impacto do neopentecostalismo no campo religioso afro-brasileiro. São Paulo: Edusp, 2007.

SOBREIRA, Ramon Fiori Fernandes. Práticas religiosas Afro-Brasileiras, marco regulatório e uso do meio ambiente. Rio de Janeiro: Univesidade do Estado do Rio de Janeiro, 2011. Sobreira, Ramon Fiori Fernandes; Machado, Carlos José Saldanha; Vilani, Rodrigo Machado. A criminalização das religões afro-brasileiras. Direitos Culturais, Santo Ângelo, v. 11, n. 24, p. 55-76, jan./abr. 2016.

Stepan, Nancy Leys. Eugenia no Brasil, 1917-1940. In: Hochman, G.; Armus, D. Cuidar, controlar, curar: ensaios históricos sobre saúde e doença na América Latina e Caribe. Rio de Janeiro: Editora FIOCRUZ, 2004. p. 330-391.

Teeb - The Economics Of Ecosystems And Biodiversity. The Economics of Ecosystems and Biodiversity: Ecological Economics Foundations. London and Washington,: Earthscan., 2010.

Theodoro, Helena. Religiões Afro-Brasileiras. In: NAscimento, E. L. Guerreiras da natureza: mulher negra, religiosidade e ambiente. São Paulo: Selo Negro, 2008. p. 65-84.

TrevisAn, Janine. A Frente Parlamentar Evangélica: força política no estado laico brasileiro. Numen, Juiz de Fora, v. 16, n. 1, p. 581-609, 2013.

UnEsCo. Unesco reconhece capoeira como Patrimônio Cultural Imaterial da Humanidade. $D W$, 2014. Disponivel em: https://p.dw.com/p/1DuEF. Acesso em: 17/o9/2020. 
Wild, Robert; Mcleod, Christopher. Sitios Sagrados Naturales: Directrices para Administradores de Áreas Protegidas. 16 ed. Gland: IUCN, 2008.

Young, Carlos Eduardo Freckmann; Spanholi, Maira Luiza. Uma visão econômica sobre a conservação da biodiversidade e serviços ecossistêmicos. Com Ciência, 2020. Disponivel em: https://www.comciencia.br/uma-visao-economica-sobre-aconservacao-da-biodiversidade-e-servicos-ecossistemicos/. Acesso em: 11/10/ 2020. 